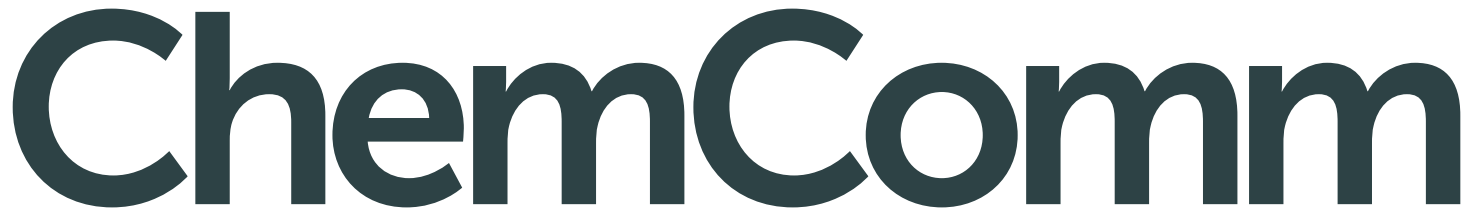

Chemical Communications

www.rsc.org/chemcomm
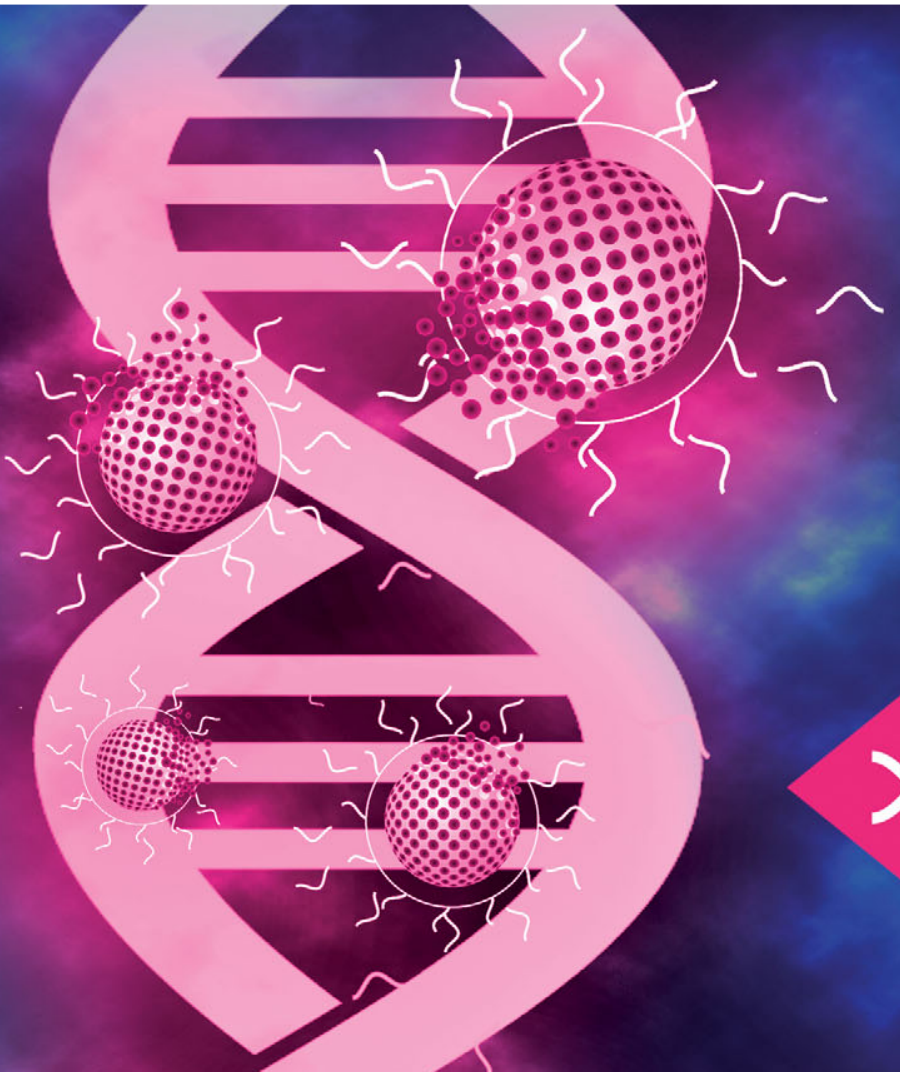

\title{
XIIC
}
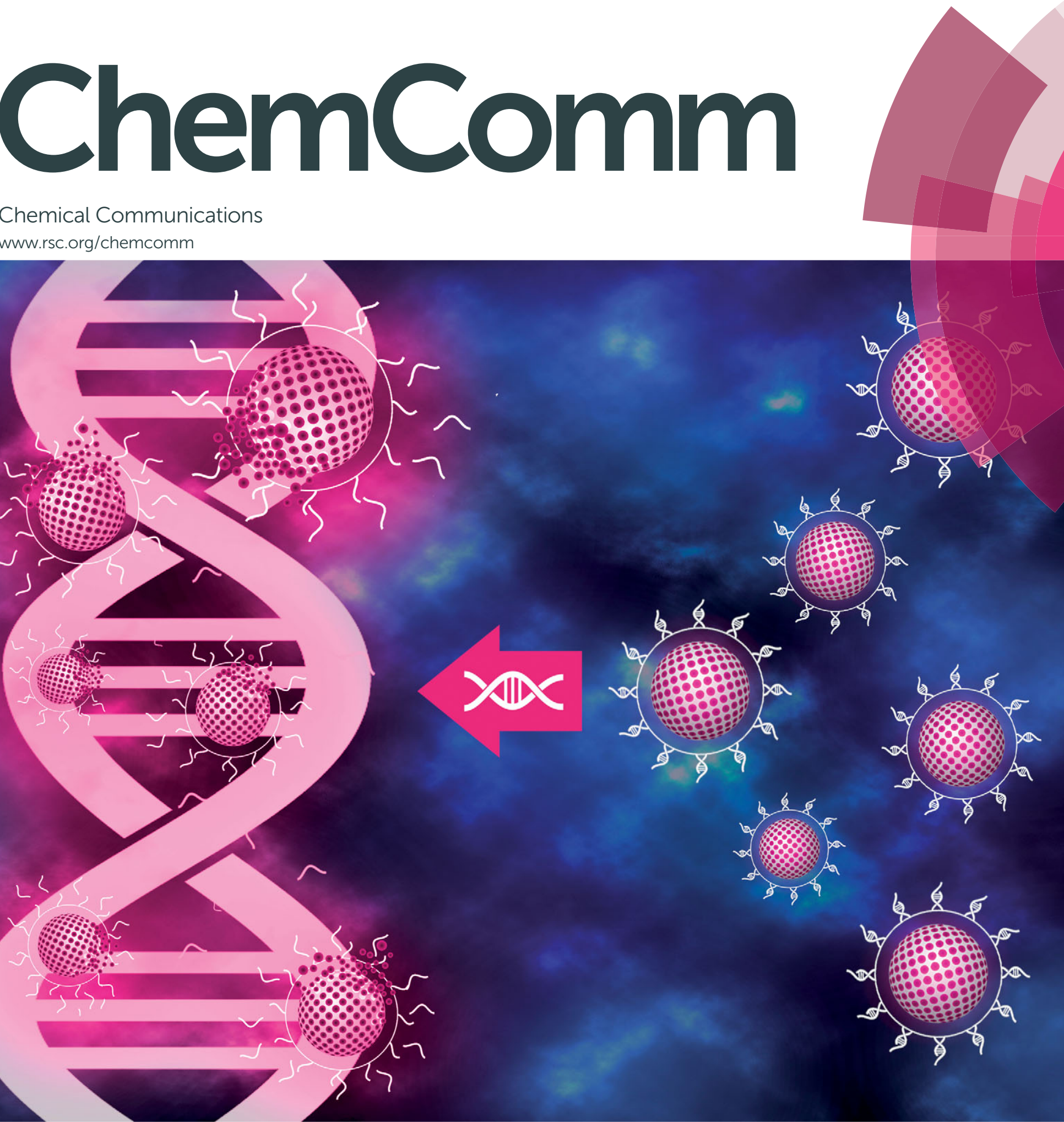

$\curvearrowright$

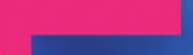

S
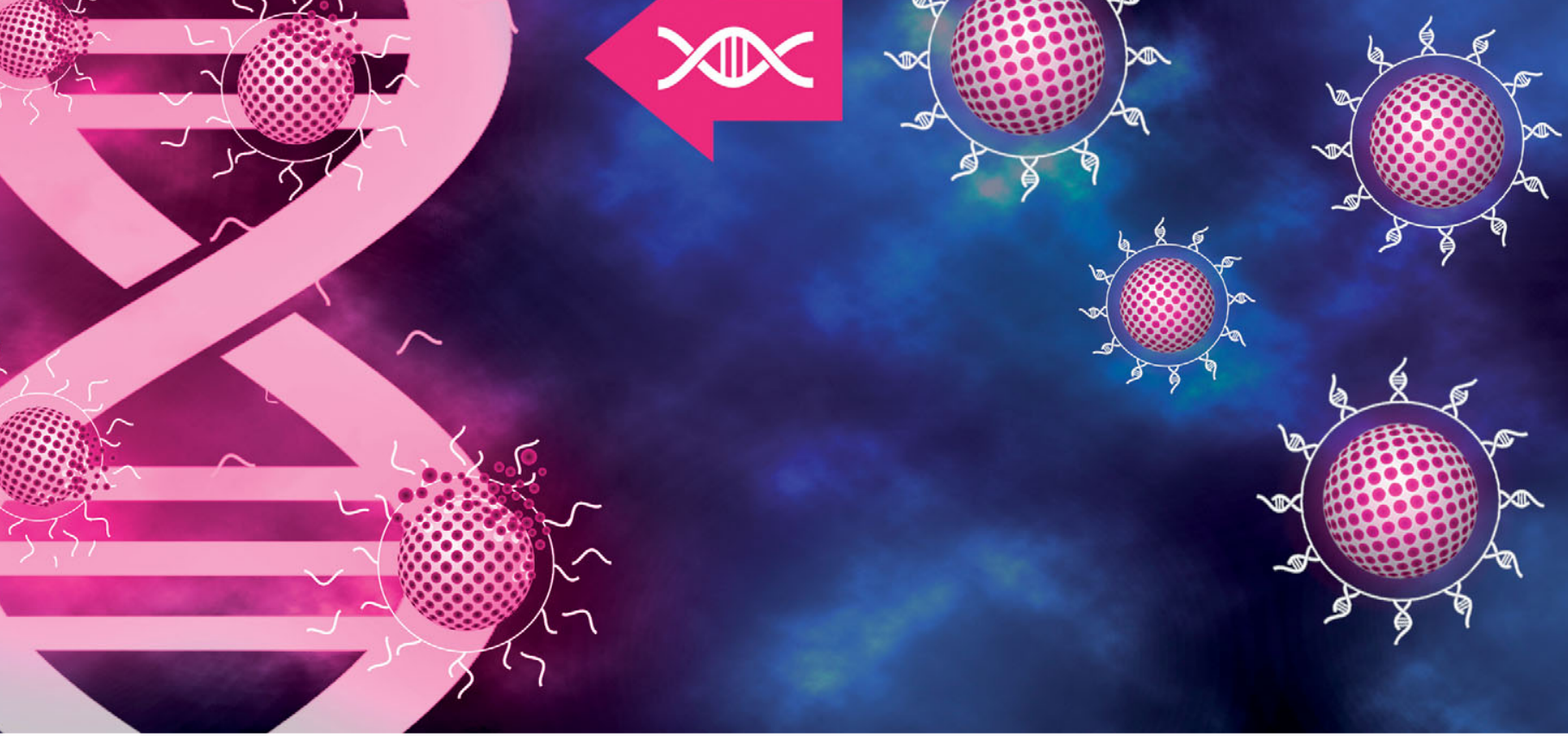

ISSN 1359-7345

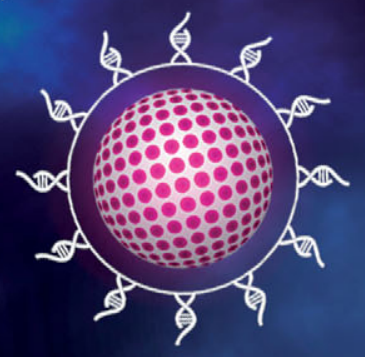




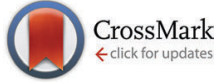

Cite this: Chem. Commun., 2015, 51, 1414

Received 21st October 2014, Accepted 18th November 2014

DOI: $10.1039 / \mathrm{c} 4 \mathrm{cc} 08306 \mathrm{~g}$

www.rsc.org/chemcomm

\section{Oligonucleotide-capped mesoporous silica nanoparticles as DNA-responsive dye delivery systems for genomic DNA detection $\dagger$}

\author{
Lluís Pascual, ${ }^{a b c}$ Isabel Baroja, ${ }^{a b c}$ Elena Aznar, ${ }^{a c}$ Félix Sancenón, ${ }^{a b c}$ \\ M. Dolores Marcos, ${ }^{a b c}$ Jose Ramón Murguia, ${ }^{a b c}$ Pedro Amorós, ${ }^{d}$ Knut Rurack ${ }^{e}$ and \\ Ramón Martínez-Máñez *abc
}

\begin{abstract}
New hybrid oligonucleotide-capped mesoporous silica nanoparticles able to detect genomic DNA were designed.
\end{abstract}

Nanodevices equipped with molecular gates based on mesoporous silica nanoparticles have proven their potential for use in biological and medical applications. ${ }^{1}$ So far, capped materials have been mainly used in drug delivery and their use in sensing protocols is still scarce. ${ }^{2}$ For sensing, the mesoporous support is loaded with an indicator before the material is capped with a responsive chemistry. Uncapping and cargo delivery is then selectively achieved only in the presence of a target analyte. ${ }^{3}$ In this context we are interested in the use of DNA sequences for the design of gated materials and others and we have recently reported the use of oligonucleotides as caps on mesoporous supports in the context of the detection of biomolecules via delivery of optical or electro-active probes. ${ }^{4}$ However, in this context, the detection of genomic DNA using capped materials is still very rare.

Inspired by these preliminary studies we report herein a new hybrid gated material with a covalently attached double-stranded DNA (dsDNA) sequence that selectively delivers a dye in the presence of genomic DNA. As a proof of concept the detection of Mycoplasma genomic DNA was pursued in this work. Detection of bacteria of genus Mycoplasma is of interest in diverse areas. Mycoplasma contamination is a common problem in cell culture laboratories of research institutions and hospitals. ${ }^{5}$ Moreover, several Mycoplasma

\footnotetext{
${ }^{a}$ Centro de Reconocimiento Molecular y Desarrollo Tecnológico (IDM),

Unidad Mixta Universidad Politécnica de Valencia-Universidad de Valencia, Spain

${ }^{b}$ Departamento de Química, Universidad Politécnica de Valencia,

Camino de Vera s/n, 46022, Valencia, Spain.E-mail: rmaez@qim.upv.es

${ }^{c}$ CIBER de Bioingeniería, Biomateriales y Nanomedicina (CIBER-BBN), Spain

${ }^{d}$ Institut de Ciència dels Materials (ICMUV), Universitat de València,

P.O. Box 2085, 46071 Valencia, Spain

${ }^{e}$ Fachbereich 1.9 Sensormaterialien, Bundesanstalt für Materialforschung und -prüfung (BAM), Richard-Willstätter-Straße 11, 12489 Berlin, Germany

$\dagger$ Electronic supplementary information (ESI) available: Synthesis of S1-I and S1-01/O2 materials, characterization of the prepared solids, and release experiments with solid S1-O1/O2. See DOI: 10.1039/c4cc08306g
}

species are related to the development of certain pathologies such as pneumonia, rheumatoid arthritis and non-gonococcal urogenital diseases. $^{6}$

The approach we followed is depicted in Scheme 1. MCM-41 mesoporous silica nanoparticles of $c a .100 \mathrm{~nm}$ diameter were selected as inorganic supports because of their unique and advantageous properties for the design of capped materials. The MCM-41 support was first loaded with the dye rhodamine B and then the external surface was functionalized with (3-isocyanatopropyl)triethoxysilane, yielding solid S1-I. For the gating mechanism two single stranded oligonucleotides were selected; i.e. (i) a short DNA sequence, functionalized with an aminohexyl moiety at the $5^{\prime}$-end position $\left(\mathrm{NH}_{2}-\left(\mathrm{CH}_{2}\right)_{6}-5^{\prime}\right.$-GAC TAC CAG GGT ATC-3', O1) that could be covalently attached to solid S1-I via the formation of urea bonds and (ii) a single stranded oligonucleotide (5'-AAG CGT GGG GAG CAA ACA GGA TTA GAT ACC CTG GTA GTC-3', O2)

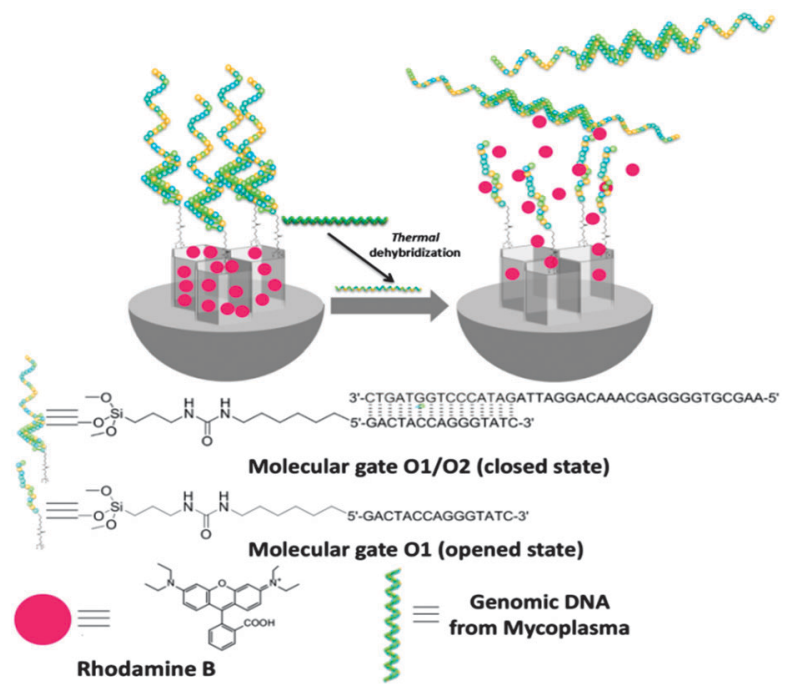

Scheme 1 Representation of the gated material S1-01/O2 capped with a dsDNA. Delivery of the entrapped dye (rhodamine B) is selectively accomplished in the presence of a single strand of Mycoplasma genomic DNA. 
which is a highly conserved sequence of the $16 \mathrm{~S}$ ribosomal subunit of the Mycoplasma species genome.

In a typical experiment the two single stranded DNA sequences (O1 and O2) were first hybridized and then covalently attached to the surface of the S1-I solid, yielding the final material S1-O1/O2. The dsDNA, anchored on the mesoporous support, was expected to be bulky enough to block the pores and inhibit dye delivery. Moreover it was anticipated that the presence of a single strand of Mycoplasma genomic DNA would displace $\mathbf{O} 2$ from the solid with the subsequent pore opening and dye release.

MCM-41 nanoparticles were obtained according to reported procedures. Solid S1-I was first loaded with rhodamine B in acetonitrile and then an excess of (3-isocyanatopropyl)triethoxysilane was added to the suspension. Solid S1-I was collected by centrifugation, washed with acetonitrile and dried (see $\mathrm{ESI} \dagger$ for details). For the preparation of the final capped material (i.e. S1-01/O2) 01 and 02 were first mixed, heated at $90{ }^{\circ} \mathrm{C}$ and then gradually cooled to achieve the hybridization of both oligonucleotides. Then the hybridized 01/O2 sequences were anchored onto the outer surface of the S1-I solid through the formation of a urea bond by reaction of the amine group in $\mathbf{0 1 / 0 2}$ and the isocyanatopropyl groups attached on S1-I (see ESI $\uparrow$ for further details).

The starting MCM-41-like calcined nanoparticles and S1-I were characterized by powder X-ray diffraction, TEM, porosimetry, thermogravimetry and elemental analysis (see ESI $\dagger$ for details). Table 1 summarizes the particle diameter, BET specific surface area, pore volumes and pore sizes obtained for the starting nanoparticles and for solid S1-I. Moreover, from elemental and thermogravimetric analyses contents of 0.469 and $0.358 \mathrm{mmol} \mathrm{g}^{-1}$ for isocyanatopropyl moieties and rhodamine $\mathrm{B}$, respectively, were determined in solid S1-I. Finally, dynamic light scattering studies in water gave diameters for the MCM-41, S1-I and S1-01/O2 nanoparticles of $88 \pm 2,114 \pm 3$ and $154 \pm 2 \mathrm{~nm}$, respectively.

The response of $\mathbf{S 1 - 0 1 / 0 2}$ was tested in the presence of Mycoplasma fermentans genomic DNA by measuring the emission of rhodamine $\mathrm{B}$ dye delivered from the pores of the solid. In a typical experiment $0.2 \mathrm{mg}$ of S1-01/O2 were suspended in $400 \mu \mathrm{L}$ of hybridization buffer ( $20 \mathrm{mM}$ tris- $\mathrm{HCl}, 37.5 \mathrm{MgCl}_{2}, \mathrm{pH} 7.5$ ) and separated into 2 aliquots of $200 \mu \mathrm{L}$. Both samples were filled to a final volume of $900 \mu \mathrm{L}$ with hybridization buffer. At the same time a solution of 4000 copies $\mu \mathrm{L}^{-1}$ of Mycoplasma fermentans quantification standard in water was heated to $95{ }^{\circ} \mathrm{C}$ for $5 \mathrm{~min}$ in order to dehybridize the double helix structure and then cooled in an ice bath for $3 \mathrm{~min}$. After cooling, $100 \mu \mathrm{L}$ of the dehybridized genomic solution was added to one of the aliquots whereas $100 \mu \mathrm{L}$ of water (that was subjected to the same thermal treatment) were added to the other aliquot. Both suspensions were maintained at $25{ }^{\circ} \mathrm{C}$

Table 1 Main structural properties calculated from TEM and $\mathrm{N}_{2}$ sorption analysis

\begin{tabular}{llcll}
\hline Sample & $\begin{array}{l}\text { Diameter } \\
\text { particle }(\mathrm{nm})\end{array}$ & $\begin{array}{l}S_{\mathrm{BET}} \\
\left(\mathrm{m}^{2} \mathrm{~g}^{-1}\right)\end{array}$ & $\begin{array}{l}\text { Pore volume }^{a} \\
\left(\mathrm{~cm}^{3} \mathrm{~g}^{-1}\right)\end{array}$ & $\begin{array}{l}\text { Pore size }^{a} \\
(\mathrm{~nm})\end{array}$ \\
\hline MCM-41 & $80 \pm 4$ & 1228.2 & 0.93 & 2.40 \\
S1-I & $80 \pm 3$ & 524.9 & 0.34 & 2.40
\end{tabular}

${ }^{a} \mathrm{BJH}$ model.

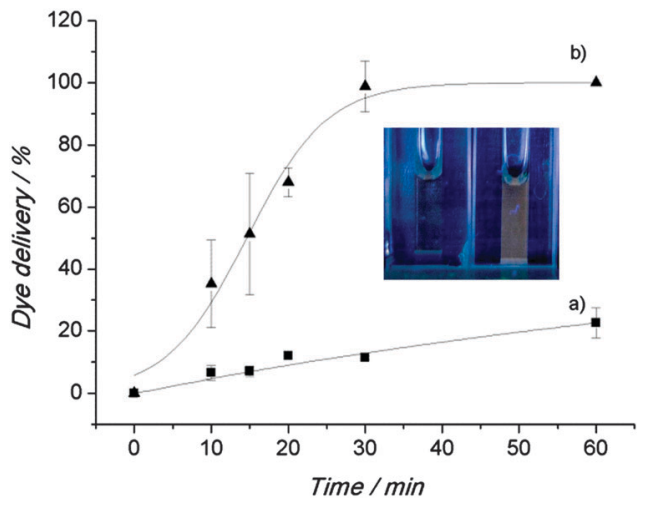

Fig. 1 Release of rhodamine B from solid S1-01/O2 in (a) the absence and (b) in the presence of Mycoplasma fermentans genomic DNA (4000 copies $\mu \mathrm{L}^{-1}$ ) in Tris- $\mathrm{HCl}$ buffer at $\mathrm{pH} 7.5$. The inset shows the emission changes (under UV lamp, excitation at $254 \mathrm{~nm}$ ) of the rhodamine $B$ released from solid S1-01/O2 in the absence (left) and in the presence (right) of Mycoplasma fermentans genomic DNA (4000 copies $\mu \mathrm{L}^{-1}$ ).

and, at certain times, fractions were taken and centrifuged to eliminate the solid. Cargo release to the solution was then measured by the rhodamine $\mathrm{B}$ fluorescence at $575 \mathrm{~nm}\left(\lambda_{\mathrm{exc}}=\right.$ $555 \mathrm{~nm}$ ). Fig. 1 shows the delivery profile of rhodamine B from solid S1-O1/O2 in the presence and in the absence of Mycoplasma fermentans genomic DNA. As it can be seen, in the absence of the target DNA (Fig. 1, curve a) a poor rhodamine B delivery was observed (less than $15 \%$ after $1 \mathrm{~h}$ ) indicative of a remarkable pore closure. In contrast, in the presence of Mycoplasma genomic DNA, the pores were opened due to the displacement of oligonucleotide O2 from the solid S1-O1/O2 with the subsequent delivery of the dye (Fig. 1, curve b). Under these conditions ca. 90\% of the maximum delivery of rhodamine B was observed after $30 \mathrm{~min}$.

The high performance of solid S1-01/02 pointed to the effective anchoring of the 01/02 dsDNA on the external surface of the inorganic scaffold through the formation of urea bonds. Additional experimental evidence of the correct grafting arose from the fact that solid S1-01/O2 was able to deliver rhodamine B in the presence of urease, due to the enzyme-induced hydrolysis of this bond with the subsequent detachment of the $01 / 02$ double strand (see $\mathrm{ESI} \dagger$ ). Moreover, in the presence of DNAse I, a remarkable dye release was also observed indicating the crucial role played by the $\mathbf{0 1 / 0 2}$ sequence in the capping protocol (see ESI $\dagger$ ).

The next step was to assess the sensitivity of S1-01/O2 nanoparticles towards genomic DNA with the determination of the limit of detection. Following a procedure similar to that described above various solutions with different concentrations of Mycoplasma fermentans genomic DNA were added to several suspensions of S1-O1/O2 and the rhodamine B released after 30 min was measured (see ESI $\dagger$ ). A correlation between the number of copies of Mycoplasma genomic DNA added and the rhodamine B delivered was found in agreement with an uncapping process related to the displacement of $\mathbf{O 2}$ from the S1-01/O2 solid. A limit of detection of $c a$. 70 DNA copies $\mu \mathrm{L}^{-1}$ was determined (see ESI $\dagger$ ). The limit of detection following this simple approach is not far from those reported using 


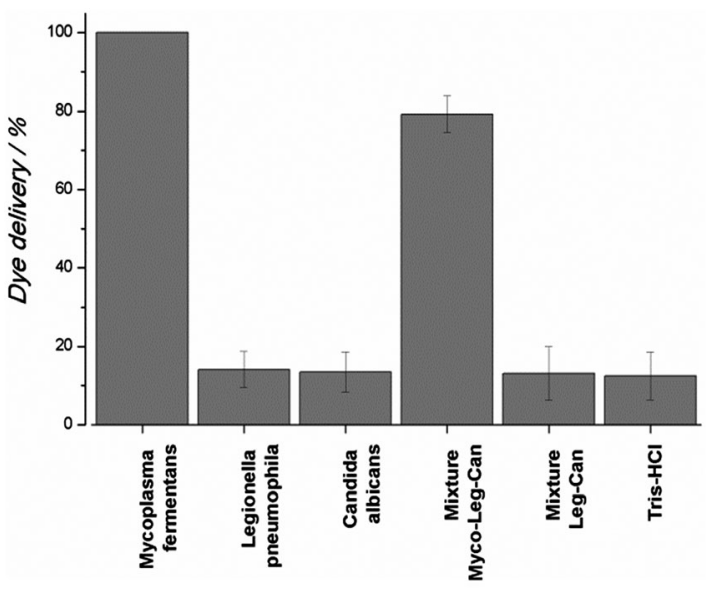

Fig. 2 Release of rhodamine B from solid S1-01/O2 in the presence of (from right to left): Tris- $\mathrm{HCl}$ buffer, a mixture of Legionella pneumophilaCandida albicans (Leg-Can) genomic DNA, a mixture of Leg-Can and Mycoplasma fermentans (Myco) genomic DNA, Can genomic DNA, Leg genomic DNA and Myco genomic DNA. All DNA were at a concentration of 1000 copies $\mu \mathrm{L}^{-1}$.

commercially available PCR Mycoplasma detection kits (around ca. 10 copies $\left.\mu \mathrm{L}^{-1}\right),{ }^{7}$ suggesting that this procedure for genomic DNA sensing possesses the potential of finding application in medical diagnosis protocols.

In further studies the selectivity in the detection of Mycoplasma genomic DNA by the S1-O1/O2 solid was investigated by carrying out similar experiments in the presence of genomic DNA of the pathogens Candida albicans and Legionella pneumophila in amounts of 1000 copies $\mu \mathrm{L}^{-1}$. The results obtained are shown in Fig. 2. As can be seen there were no significant differences between the blank (dye release in Tris-HCl buffer) and the potentially interfering genomic DNA of Candida albicans and Legionella pneumophila. In addition, when a mixture of Candida albicans-Legionella pneumophila (each one at a concentration of 1000 copies $\mu \mathrm{L}^{-1}$ ) was used no delivery of rhodamine B was observed. Furthermore, when genomic DNA of Mycoplasma was present in the mixture a clear delivery of rhodamine B was found pointing to a high degree of selectivity of the S1-01/O2 material.

In summary, we have prepared mesoporous silica nanoparticles loaded with rhodamine B and capped with a covalently linked double stranded DNA containing a highly conserved sequence of the $16 \mathrm{~S}$ ribosomal subunit of the Mycoplasma species genome. The nanoparticles were able to deliver the entrapped dye in the presence of Mycoplasma fermentans genomic DNA. A remarkable detection limit of $c a$. 70 DNA copies $\mu \mathrm{L}^{-1}$ was found. Moreover the selectivity of the system was assessed, for instance, addition of Candida albicans and Legionella pneumophila genomic DNA was unable to induce dye release. We believe that DNA-based gated materials could be suitable alternatives to the standard bacteria detection techniques such as PCR and can find application as alternative rapid point-of-care diagnostic systems or in situations and places where sophisticated techniques or equipment are not available.

Financial support from the Spanish Government (Project MAT2012-38429-C04) and the Generalitat Valencia (Project PROMETEOII/2014/047) is gratefully acknowledged. Ll. P. is grateful to the Universidad Politécnica de Valencia for his grant.

\section{Notes and references}

1 (a) A. Agostini, L. Mondragón, A. Bernardos, R. Martínez-Máñez, M. D. Marcos, F. Sancenón, J. Soto, A. Costero, C. Manguan-García, R. Perona, M. Moreno-Torres, R. Aparicio-Sanchis and J. R. Murguía, Angew. Chem., Int. Ed., 2012, 51, 10556-10560; (b) Q. Zhang, X. Wang, P.-Z. Li, K. T. Nguyen, X.-J. Wang, Z. Luo, H. Zhang, N. S. Tan and Y. Zhao, Adv. Funct. Mater., 2014, 24, 2450-2461; (c) C. Chen, J. Geng, F. Pu, X. Yang, J. Ren and X. Qu, Angew. Chem., Int. Ed., 2011, 50, 882-886; (d) L. Zhou, Z. Chen, K. Dong, M. Yin, J. Ren and X. Qu, Adv. Mater., 2014, 26, 2424-2430.

2 (a) A. Agostini, L. Mondragón, L. Pascual, E. Aznar, C. Coll, R. Martínez-Máñez, F. Sancenón, J. Soto, M. D. Marcos, P. Amorós, A. M. Costero, M. Parra and S. Gil, Langmuir, 2012, 28, 14766-14776; (b) C. Coll, A. Bernardos, R. Martínez-Máñez and F. Sancenón, Acc. Chem. Res., 2013, 46, 339-349; (c) E. Climent, R. Martínez-Máñez, A. Maquieira, F. Sancenón, M. D. Marcos, E. M. Brun, J. Soto and P. Amorós, ChemistryOpen, 2012, 1, 251-259.

3 (a) M. Oroval, E. Climent, C. Coll, R. Eritja, A. Avino, M. D. Marcos, F. Sancenon, R. Martinez-Manez and P. Amoros, Chem. Commun., 2013, 49, 5480-5482; (b) M. Chen, C. Huang, C. He, W. Zhu, Y. Xu and Y. Lu, Chem. Commun., 2012, 48, 9522-9524.

4 (a) E. Climent, R. Martínez-Máñez, F. Sancenón, M. D. Marcos, J. Soto, A. Maquieira and P. Amorós, Angew. Chem., Int. Ed., 2010, 49, 7281-7283; (b) E. Climent, L. Mondragón, R. Martínez-Máñez, F. Sancenón, M. D. Marcos, J. R. Murguía, P. Amorós, K. Rurack and E. Pérez-Payá, Angew. Chem., Int. Ed., 2013, 52, 8938-8942; (c) Z. Zhang, D. Balogh, F. Wang, S. Y. Sung, R. Nechushtai and I. Willner, ACS Nano, 2013, 7, 8455-8468; (d) L. Wu, J. Ren and Q. Xiaogang, Nucleic Acids Res., 2014, DOI: 10.1093/nar/gku858.

5 H. Drexler and C. Uphoff, Cytotechnology, 2002, 39, 75-90.

6 (a) L. Matas Andreu, S. Molinos Abós, G. Fernández Rivas, V. González Soler and V. Ausina Ruiz, Enferm. Infecc. Microbiol. Clin., 2006, 24, 19-23; (b) V. Ausina, Infecciones causadas por micoplasmas, Medicina Interna, Elsevier España, 2004, 15th edn, pp. 2363-2365.

7 (a) http://www.lifetechnologies.com; (b) http://www.sigmaaldrich. com; (c) http://www.lgcstandards-atcc.org (all websites accessed on 01/10/2014). 